Article Review

\title{
Nisbah kelamin dan ukuran pertama kali matang gonad bulu babi Tripneustes gratilla (Linnaeus, 1758)
}

\author{
Nova Damayanti Girsang* \\ *Jurusan Manajemen Sumber Daya Perairan, Fakultas Perikanan dan IImu Kelautan, Universitas Negeri Gorontalo. \\ Email: girsangnova1@gmail.com
}

\section{Introduction}

Hewan laut yang kebanyakan di jumpai pada ekosistem padang lamun di peraian pantai disebut bulu babi. Bulu babi yang merupakan hewan yg memiliki hubungan yang unik yaitu hubungan simbiosis dengan ikan yang menggunakan dan menunjang sekaligus ekosistem lamun (Romimohtarto dan Juwana, 2005 dalam Waters, 2010 ; Keesing and Hall, 1998 dalam Purbiantoro, et al., 2014; Aziz, 1994: 36 dalam Lubis, et a., 2017; Brusca and Brusca, 1990 dalam Wulandewi, et al., 2015; Radjab, 2004 dalam Suriani, et al., 2020). Bulu babi dapat dibagi dalam dua subkelas sesuai bentuh tubuhnya, yaitu bulu babi beraturan (regular urchin) dan bulu babi tidak beraturan (irregular urchin). Bentuk tubuh hemisfer yaitu bentuk tubuh yang merata di bagian bawah dan membuat dibagian atas dan bentuk tubuh ini dimiliki bulu babi kelompok reguler. Hewan ini memiliki duri yang panjang dan kadang berwarna menyolok dimiliki bulu babi kelompok reguler. Sedangkan kelompok bulu babi yang memiliki bentuk tubuh yang memipih adalah kelompok irregular. Kelompok bulu babi beraturan salah satunya bulu babi Tripneustes gratilla. Pada umumnya bulu babi beraturan mempunyai struktur cangkang berbentuk bola yang biasanya oval atau sirkural dan pada bagian oral dan aboral agak pipih umumnya dimiliki bulu babi beraturan (Radjab, 2001; Gunarto, 2002 dalam Firmandana, 2014).

Tidak hanya fungsi ekologis yang dimiliki, tetapi gonad bulu babi ini sangat menguntungkan dijadikan bahan pangan (Nane, 2019a; 2019b). Uni adalah nama dari gonad bulu babi yang dikenal di pasaran (Pearce, et al., 2004 dalam Puspitaningtyas, et al., 2018), dan di berbagai Negara seperti Jepang, Prancis, Chili, Amerika Serikat, Barbados, Rusia, dan Kanada merupakan konsumen dari gonad bulu babi dan gonad bulu babi merupakan salah satu komoditi ekspor utama Negara tersebut (Daggett, et al. 2005; Hammer et al. 2006 dalam Nasrullah,et al., 2018; Daggett, et al. 2005 dalam Putra, et al., 2017; Zakaria, 2013; Darsono \& Sukarno, 1993 dalam Yulianto, 2012; Aslan 2005; Dagget et al., 2005; Hammer et al., 2006 dalam Uneputty, 2017; Nane, 2019c). Di pasaran 
internasional harga gonad bulu babi berkisar US\$6 hingga \$200 per kilogram (Robinson, et al. 2002 dalam Waters, 2010). Echinometra mathaci, Echinotrix sp, Salmacis sp, Deadema setosum dan Tripneustes gratilla adalah jenis gonad bulu babi yang banyak digunakan sebagai bahan pangan (Setiabudi dan Murnyati, 1998; Darsono, 1982 dalam Waters, 2010; Nane et al. 2020). Bulu babi dimanfaatka dengan cara penambilan gonad dan digunakan sebagai bahan makanan (Vimono, 2007 dalam Lawi, et al., 2019; Nontji, 1987 dalam Fraulaine dan Akobiarek, 2016; Rachmawaty, 2004 dalam Hadinoto, et al., 2018; Vimono 2007 dalam Suseno dan jacoeb, 2014).

Bulu babi hidup di padang lamun bisa hidup sendiri atau hidup mengelompok, tergantung kepada habitat dan jenisnya (Nane, 2019d). Contoh bulu babi yang cenderung hidup secara berkelompok adalah Strongylocentrotus spp, D. antillarum, Temnopleurus toreumaticus, Diadema setosum, T. ventricosus, Tripneustes gratilla dan Lytechinus variegatus. Sedangkan contoh dari bulu babi yang cenderung hidup secara sendiri adalah Echinothric diadema, Mespilia globulus, Pseudoboletia maculate dan Toxopneustes pileolus (Aziz, 1994 dalam Firmandana 2014; (Aziz, 1994 dalam Yolanda, et al., 2017). Jenis lamun Halodule uninervis cenderung dipilih bulu babi Echinothrix calamaris, Tripneustes gratilla dan Mespilia globulus daripada jenis lamun lainnya (Andi dan Inayah, 2012; Haerul, 2011 dalam Laning, et al., 2014). Kedalaman 5000 meter, bulu babi juga dapat ditemukan (Suwignyo et al., 2005 dalam Lawi, et al., 2019; Brusca dan Brusca, 2003 dalam Ayuwati, 2017; Basir, 2014; Suwignyo. 2005 dalam Tanjung, 2017).

Di beberapa Negara, bulu babi sudah over fishing dan produksinya menurun, sedangkan dari tahun ke tahun permintaan atas komoditas ini meningkat (Hammer et al. 2006; Siikavuopio et al. 2006 dalam Puspitaningtyas, et al., 2018). Produksi yang mengandalkan dari hasil tangkapan mengakibatkan belum terpenuhinya permintaan bulu babi. Sehingga banyak orang berupaya melakukan penangkapan bulu babi dari alam, kelestarian biota secara perlaham akan terganggu. Oleh karena itu, pembenihan bulu babi dan budidayanya segera dikembangkan untuk meningkatkan produksi dan supaya di alam terjaga kelestarian bulu babi. Benih bulu babi saat ini masih dari alam yang mengakibatkan pengaruh kesinambungan produksi, karena pengembangan pembenihan dan pembudidayaan belum terlaksanakan. Sebagai data awal saat akan memulai usaha pembenihan maka perlu dikaji masalah biologi reproduksi bulu babi. Kondisi geografis dan musim mempengaruhi siklus reproduksi bulu babi, dari suatu tempat ke tempat lainnya IKG bulu babi bervariasi sehingga perlu di ketahui aspek reproduksi seperti IKG secara lokal. (Siikavuopio et al. 2006 dalam Lawi, et al., 2019). Pada saat akan terjadi pemijahan IKG akan mencapai batas maksimum dan akan turun kembali setelah pemijahan (Effendie, 1997 dalam Nasrullah,et al,. 2018).

Individu Bulu babi Tripneustes gratilla dengan gonad mulai berkembang sampai memijah dan pulih ditemukan pada setiap bulan pengamatan. Hal ini disebabkan karena perkembangan gonad 
yang asinkronis dimiliki oleh bulu babi Tripneustes gratilla. Tipe pemijahan yang berlangsung secara terus menerus sepanjang tahun dan puncak pemijahan bisa pada pertengahan ataupun akhir tahun, tipe ini terindikasi dari Pola perkembangan gonad bulu babi Tripneustes gratilla (Aslan, 2005 dalam Waters, 2010).

Terjadi dalam empat tahap saat proses gametogenesis atau pembentukan gonad, yaitu inter gametogenesis, pre gametogenesis, gametogenesis dan akhir gametogenesis adalah pemijahan. Lama waktu yang dibutuhkan untuk seluruh tahap itu adalah 10-15 bulan, karena dari tahap gametogenesis dan pre gamtogenesis terkadang terjadi overlapping. Ukuran dan jumlah Granula dan globul kuning telur bertambah dan mengakibatkan bertambahnya volume oosit. IKG akan meningkat dan bobot gonad juga akan bertambah karena adanya aktivitas dari oosit (Yaron, 1995 dalam Waters, 2010).

Ukuran diameter telur dan pola IKG sama arah denganpola warna gonad. Warna akan berubah sesuai dengan tingat perkembangan warna, peningkatan perubahan warna ini dan peningkatan ukuran diameter telur akan mengikuti peningkatan IKG. Fase perkembangan gonad berhubungan dengan kualitas warna gonad. Pada fase pematangan awal, pra matang atau pada fase pertumbuhan umumnya dapat ditemukan warna gonad yang berkualitas tinggi, sedangkan pada fase matang akhir dan fase puih atau menjelang pemijahan umumnya dapat ditemukan kualitas warna gonad yang rendah. Pada fase matang gonad atau pada fase pertumbuhan menghasilkan produksi dan kualitas gonad yang maksimal (Unuma et al., 1999 dalam Tupan dan br. Silaban, 2017; Effendie, 1997 dalam Yusrika, 2015).

Gonad bulu babi berisi sel- sel fagosit nutritive dan sel-sel gamet. Ukkuran diameter oosit (pada betina), kepadatan sel-sel gamet, keberadaan sel-sel yang dominan, pergerakan sel-sel gamet ke pusat lumen folikel dan ukuran ketebalan lapisan folikel merupakan ciri- ciri dari tahapan perkembangan gonad. Perkembangan spermatosit priemr dan spermaatogonium atau oosit primer dan oogonium menempel di dinding folikel dan berada di antara sel fagosit nutritive, perkembangan ini menunjukkan perkembangan gonad baik pada betina maupun jantan (Waters, 2010)

Perkembangan gonad bulu babi di mulai dengan mendominasinya sel fagosit nutritive yang memiliki lapisan folikel yang tipis. Ketebalan lapisan folikel meningkat dan sel- sel fagosit nutritif berkurang jumlahnya merupakan proses yang terjadi saat perkembangan gonad dan terjadi hingga pada tahap matang gonad. Pada saat kematangannya, oosit ataupun spermatosit kepadatannya akan bertambah dan akan bergerak menuju pusat lumen folikel. Ketebalan lapisan folikel menurun dan kumpulan spermatozoa ataupun oosit yang padat dan terakumulasi di pusat lumen folikel dan tidak memiliki sel-sel nutritif phagosit merupakan pertanda dari gonad yang sudah matang. Saat selsel fagosit nutritive bertambah dan mengakibatkan menebalnya dinding folikel, ini merupakan 
tahapan partial spawning dan tahapan ini juga kepadatan spermatozoa maupun oosit menurun dengan ruang kosong yang terlihat jelas dalam lumen. Sedangkan pada ikan teleleostei dapat ditemui perbedaan, yaitu spermatogonia ataupun oogonia tersusun secara acak tersebar satu demi satu dan tidak ada pengaturan urutan (Waters, 2010)

Bahan dasar untuk informasi pembenihan pada proses budidaya bulu babi dapat diperoleh dari penelitian yang bertujuan untuk mengetahui aspek reproduksi seperti IKG pada suatu tempat dibedakan menurut musim dan kondisi geografis (Tjendawangi \& Dahoklory, 2013). 1;1 merupakan perbandingan antara jantan dan betina secara alamiah di suatu perairan yang normal ( Bal \& Rao,1984 dalam Faizah, et al., 2016). Nikolsky (1963) dalam Gustomi (2017). Habitat ikan sangat berkaitan erat dengan nisbah kelamin. Habitat yang umumnya memiliki jumlah ikan jantan dan ikan betina yang seimbang merupakan habitat yang ideal untuk melakukan pemijahan (Nikolsky, 1963 dalam Gustomi dan Sulistiono, 2016). Muthiga (2005) dalam Lawi, et al., 2019, mendapatkan nisbah kelamin yang hampir mendekati nisbah kelamin yang seimbang atau $1: 1$, yaitu kelamin bulu babi (Tripneustes gratilla Linnaeus 1758) ditemukan pada tiga tempat berbeda di Kenya antara lain Vipingo 1:1, Diani 0.67:1, dan Kanamai 0.69:1.

Gonad bulu babi betina memiliki ukuran pertama kali matang lebih besar pada ekosistem berpasir atau ekositem lamun daripada gonad bulu babi jantan. Ketersediaan dan kelimpahan makanan pada kedua ekosistem serta pola pertumbuhan pada bulu babi jantan dan betina, ini merupakan dugaan yang menyebabkan gonad bulu babi jantan dan betina memiliki ukuran pertama kali matang berbeda. Radjab dkk (2010), mengatakan bahwa $53 \mathrm{~mm}$ adalah ukuran bulu babi yang harus diperhatikan saat akan dipanen atau eksploitasi. Pernyataan ini berhubungan dengan tingkat kematangan gonad bulu babi, karena pada saat ukuran gonad bulu babi masih kecil maka bulu babi tersebut masi berada pada fase matang awal (preliminary mature). Eklöf dkk (2009) dalam Lawi, et al., 2019 , menemukan Tripneustes gratilla dengan diameter cangkang antara 16,5-94,5 mm di Perairan Kenya. Tripneustes gratilla yang berasal dari beberapa lokasi di Perairan Papua juga memiliki diameter cangkang bervariasi masing-masing di Serui 5,8-7,7 cm, Saubeba 7,6-9,0 cm, Biak 5,0-8,7 cm, Wasior 6,2-9,3 cm dan Manokwari 5,7- 7,8 cm (Toha et.al., 2012).

Clark (1946) dalam Toha et.al., 2012), menyatakan bahwa perbedaan diameter cangkang kemungkinan berterkaitan dengan umur, bulu babi tua memiliki cangkang relatif lebih besar dan bulu babi muda umumnya memiliki ukuran cangkang kecil (Tripneustes gratilla Linnaeus 1758) 108 $\mathrm{mm}, 145 \mathrm{~mm}$ dan $155 \mathrm{~mm}$ merupakan variasi ukuran tertinggi yang dapat dicapai bulu babi dewasa. Menurut Manuel, et al., (2013), Diatas $60 \mathrm{~mm}$ adalah ukuran pertama kali matang gonad bulu babi Tripneustes gratilla. 
Bulu babi Tripneustes gratilla memiliki jenis kelamin terpisah (gonochoric) (Nane, 2019), tetapi tidak adanya perbedaan ciri jenis kelamin (dimorphism) dan sulit membedakan jenis kelamin setiap individu secara morfologi (David dkk. 1988, Giese dkk. 1991 dalam Toha.et al., 2012). Jika ada perbedaannya, maka bisa jadi perbedaan itu menyangkut ukuran atau kurang atau lebih mencolok morfologi atau sistem genital. Oleh karena itu, para ahli atau praktisi masih berusaha mencari metode praktis untuk memecahkan tantangan untuk menentukan jenis kelamin bulu babi atau salah satunya Tripneustes gratilla. Berdasarkan panjang, kehadiran dan bentuk papilla genital maka jenis kelamin bulu babi Tripneustes gratilla dapat ditentukan menggunakan model (Lawrence 1987 dalam Toha et.al., 2012). Bulu babi betina papilla genitalnya pendek dan kerucut berbentuk tonjolan tumpul (stumpy protoberances), sedangkan bulu babi jantan ditandai oleh papilla genital panjang dan berbentuk tabung. Tipe ini disebut juga tipe Tripneustus, meski membantu pola ini tidak praktis (Radjab et al., 2010; ), karena tidak dapat diakukan secara langsung dan harus mematikan dan membelah bulu babi untuk menentukan papilla genital. Jenis kelamin hewan dapat ditentukan dari Ukuran hewan. Menurut Abessa dkk. (2001) dalam Toha et.al., 2012), dengan ukuran pada hewan yang sama, jantan memiliki ukuran lebih kecil dari betina karena gonoporanya sedikit lebih kecil.

\section{Conclusion}

Hewan laut yang kebanyakan di jumpai pada ekosistem padang lamun di peraian pantai disebut bulu babi. Habitat sangat berkaitan erat dengan nisbah kelamin. Habitat yang umumnya memiliki jumlah jantan dan betina yang seimbang merupakan habitat yang ideal untuk melakukan pemijahan. perkembangan gonad yang asinkronis dimiliki oleh bulu babi Tripneustes gratilla. Perkembangan gonad bulu babi di mulai dengan mendominasinya sel fagosit nutritive yang memiliki lapisan folikel yang tipis. Ketebalan lapisan folikel meningkat dan sel- sel fagosit nutritif berkurang jumlahnya merupakan proses yang terjadi saat perkembangan gonad dan terjadi hingga pada tahap matang gonad. Gonad bulu babi betina memiliki ukuran pertama kali matang lebih besar pada ekosistem berpasir atau ekositem lamun daripada gonad bulu babi jantan. pembenihan bulu babi dan budidayanya segera dikembangkan untuk meningkatkan produksi dan supaya di alam terjaga kelestarian bulu babi.

\section{References}

Ayuwati, R. N. Pola Distribusi Jenis Echinoidea Di Zona Intertidal Tanjung Bilik Taman Nasional Baluran. Http://Repository.Unej.Ac.Id/Handle/123456789/83393 
Basir, N. (2014). Uji Antimitosis Ekstrak Etanol Larut Dan Tidak Larut N-Heksan Daun Katuk (Sauropus Androgynus L. Merr) Berdasarkan Penghambatan Pembelahan Sel Telur Bulu babi (Doctoral Dissertation, Universitas Islam Negeri Alauddin Makassar). Http://Repositori.Uin-Alauddin.Ac.Id/6486/1/Nasrawati\%20basir_Opt.Pdf

Faizah, R., Chodrijah, U., \& Dharmadi, D. (2016). Aspek Biologi Reproduksi Ikan Cucut Kacangan (Hemitriakis Indroyonoi) Di Samudera Hindia. Bawal Widya Riset Perikanan Tangkap, 4(3), 141-147. Http://Ejournal-Balitbang.Kkp.Go.Id/Index.Php/Bawal/Article/View/683/689

Firmandana, T. C. (2014). Kelimpahan Bulu Babi (Sea Urchin) Pada Ekosistem Karang Dan Lamun Di Perairan Pantai Sundak, Yogyakarta. Management Of Aquatic Resources Journal, 3(4), 4150. Https://Ejournal3.Undip.Ac.Id/Index.Php/Maquares/Article/View/7030/6774

Gustomi, A. (2017). Biologi Reproduksi Ikan Belida (Notopterus Notopterus Pallas, 1769) Di KolongBendungan Simpur, Pulau Bangka. Jurnal IImu Pertanian Indonesia, 21(1), 56-62. Http://Journal.Ipb.Ac.Id/Index.Php/Jipi/Article/View/11715/9129

Gustomi, A., \& Sulistiono, Y. (2016). Biologi Reproduksi Ikan Belida (Notopterus Notopterus Pallas, 1769) Di Kolong-Bendungan Simpur, Pulau Bangka (Reproductive Biology Featherback (Notopterus Notopterus Pallas, 1769) In Simpur Reservoir, Bangka Island). Jurnal IImu Pertanian Indonesia (Jipi), 21(1), 56-62.

Hadinoto, S., Sukaryono, I. D., \& Siahay, Y. Kandungan Gizi Bulu Babi (Diadema Setosum) Dan Potensi Cangkangnya Sebagai Antibakteri. Lambung Mangkurat University Press. Http://Ojs.Uho.Ac.Id/Index.Php/Ampibi/Article/View/5034/3757

Andi, H., \& Inayah, Y. (2012). Daya Grazing Dan Preferensi Makanan Bulu Babi Terhadap Berbagai Jenis Lamun Di Perairan Pulau Barrang Lompo, Makassar.

Laning, T. H., Yusup, D. S., \& Wiryatno, J. Sebaran Bulu Babi (Echinoidea) Di Kawasan Padang Lamun Pantai Merta Segara, Sanur-Bali. Jurnal Biologi Udayana, 18(2). Https://Ojs.Unud.Ac.Id/Index.Php/Bio/Article/View/16834/11097

Lawi, Y. S. A., Sitepu, F. G., \& Dahlan, M. A. (2019). Nisbah Kelamin Dan Ukuran Pertama Kali Matang Gonad Bulu babi Tripneustes Gratilla (Linnaeus 1758) Pada Ekosistem Lamun Dan Ekosistem Berpasir Di Pulau Barrang Lompo Sulawesi Selatan. Octopus: Jurnal IImu Perikanan, 8(2), 15-21.

Lubis, S. A., Purnama, A. A., \& Yolanda, R. (2017). Spesies Bulu Babi (Echinoidea) Di Perairan Pulau Panjang Kabupaten Bangka Tengah Provinsi Bangka Belitung. Jurnal IImiah Mahasiswa Fkip Prodi Biologi, 3(1) Http://E-Journal.Upp.Ac.Id/Index.Php/Fkipbiologi/Article/View/1134/859 
Manuel, J. I. J., Prado, V. V., Tepait, E. V., Estacio, R. M., Galvez, G. N., \& Rivera, R. N. (2013). Growth Performance Of The Sea Urchin, Tripneustes Gratilla In Cages Under La Union Condition, Philippines. International Scientific Research Journal, 1, 195-202. http://Citeseerx.Ist.Psu.Edu/Viewdoc/Download?Doi=10.1.1.685.6313\&Rep=Rep1\&Type=Pdf

Nane, L. (2019a). Efisiensi Mesin Teknologi Sapurata Dalam Mengoptimalisasi Produksi Inovasi Pangan Kukure Di Pulau Barrang Lompo, Makassar. https://doi.org/10.31230/osf.io/q8spg

Nane, L. (2019b). Impact of overfishing on density and test-diameter size of the sea urchin Tripneustes gratilla at Wakatobi Archipelago, south-eastern Sulawesi, Indonesia. BioRxiv, 727271. https://www.biorxiv.org/content/10.1101/727271v1

Nane, L. (2019c). Sea Urchin Sustainability Studies Based on Dimension Biology, Ecology and Technology at Around of Tolandono Island and Sawa Island at Wakatobi Conservation Area. https://doi.org/10.31230/osf.io/4whz6

Nane, L. (2019d). Studi Keberlanjutan Perikanan Landak Laut Berdasarkan Dimensi Biologi, Ekologi Dan Teknologi Di Sekitar Pulau Tolandono Dan Pulausawa Kawasan Konservasiwakatobi [Skripsi], Universitashasanuddin, Makassar. https://Marxiv.Org/9zdvr/

Nane, L., Baruadi, A. S. R., \& Mardin, H. (2020). The density of the blue-black urchin Echinotrix diadema (Linnaeus, 1758) in TominiBay, Indonesia. Tomini Journal of Aquatic Science, 1(1), 16-21. https://doi.org/10.37905/tjas.v1i1.5939

Nasrullah, R., Sari, W., \& Mellisa, S. (2018). Tingkat Kematangan Gonad Bulu Babi (Tripneustes Gratilla) Di Pantai Ahmad Rhangmayang Kecamatan Mesjid Raya Kabupaten Aceh Besar. Jurnal IImiah Mahasiswa Kelautan Perikanan Unsyiah, 3(1). http://Www.Jim.Unsyiah.Ac.Id/Fkp/Article/View/8529/3564

Purbiantoro, W., Utomo, N. B. P., \& Sudrajat, O. A. (2014). The Addition Of Ulva Reticulata As A Stimulant Into Artificial Feed On The Gonad Condition Of The Collector Sea Urchin (Tripneustes Gratilla Linnaeus 1758). Jurnal IImu Dan Teknologi Kelautan Tropis, 6(1). https://Doi.Org/10.29244/Jitkt.V6i1.8628

Puspitaningtyas, I. H., Rudiyanti, S., \& Sulardiono, B. (2018). Aspek Reproduksi Bulu Babi (Sea Urchin) Di Perairan Pulau Menjangan Kecil, Kepulauan Karimunjawa, Jepara (Aspects Reproduction Of Sea Urchin In The Waters Of Menjangan Kecil Island, Karimunjawa Islands, Jepara). Management Of Aquatic Resources Journal, 6(4), 564-571. https://Ejournal3.Undip.Ac.Id/Index.Php/Maquares/Article/View/21349/19867 
Putra, N. S., Sari, W., \& Muhammadar, M. (2017). Studi Kematangan Gonad Bulu Babi Di Kawasan Pantai Kecamatan Mesjid Raya, Kabupaten Aceh Besar. Jurnal IImiah Mahasiswa Kelautan Perikanan Unsyiah, 2(4). http://Www.Jim.Unsyiah.Ac.Id/Fkp/Article/View/7774/3368

Radjab, A. W., Khouw, A. S., Mosse, J. W., \& Uneputty, P. A. (2010). Pengaruh Pemberian Pakan Terhadap Pertumbuhan Dan Reproduksi Bulu babi (Tripneustes Gratilla L) Di Laboratorium. Oseanologi Dan Limnologi Di Indonesia, 36(2), 243-258.

Riau, B. T. T. K. Irvan Tanjung. http://Jurnal.Umrah.Ac.Id/Wp-Content/Uploads/Gravity_Forms/1Ec61c9cb232a03a96d0947c6478e525e/2017/08/Skripsi-2017.Pdf

Suriani, S., Latumahina, B. M., \& Hitalessy, R. B. (2020). Hubungan Populasi Makroalga (Padina Sp) Dengan Bulu Babi (Tripneustes Gratilla) Di Perairan Pantai Desa Titawaai Kabupaten Maluku Tengah. Jurnal Riset Perikanan Dan Kelautan,2(1), 165-175. http://Ejournal.UmSorong.Ac.Id/Index.Php/Jrpk/Article/View/866/527

Suseno, S. H., \& Jacoeb, A. M. (2014). Profil Asam Lemak Dan Asam Amino Gonad Bulu Babi. Jurnal Pengolahan Hasil Perikanan Indonesia, 17(1). https://Doi.Org/10.17844/Jphpi.V17i1.8138

Tjendanawangi, A., \& Dahoklory, N. (2011). Studi Reproduksi Bulu babi Tripneustes Gratilla Di Perairan Tablolong, Teluk Kupang. Fakultas Pertanian Undana: Kupang.

Tupan, J., \& Br Silaban, B. (2017). Karakteristik Fisik-Kimia Bulu Babi Diadema Setosum Dari Beberapa Perairan Pulau Ambon. Triton, 13(2), https://Media.Neliti.Com/Media/Publications/286862-Karakteristik-Fisik-Kimia-Bulu-Babi-Diad5662e2fe.Pdf

Waters, I. K. B. Perkembangan Gonad Bulu babi, Tripneustes Gratilla, Yang Ditangkap Di Perairan Teluk Kupang.

Wulandewi, N. L. E., Subagio, J. N. J. N., \& Wiryatno, J. (2015). Jenis Dan Densitas Bulu Babi (Echinoidea) Di Kawasan Pantai Sanur Dan Serangan Denpasar-Bali. Simbiosis, 3(1). https://Ojs.Unud.Ac.Id/Index.Php/Simbiosis/Article/View/14406/9902

Yolanda, R., Lubis, S. A., \& Purnama, A. A. Spesies Bulu Babi (Echinoidea) Di Perairan Pulau Panjang Kabupaten Bangka Tengah Provinsi Bangka Belitung (Doctoral Dissertation, Universitas Pasir Pengaraian). https://Media.Neliti.Com/Media/Publications/110996-Id-Spesies-Bulu-BabiEchinoidea-Di-Perairan.Pdf

Yulianto, A. R. (2012). Pemanfaatan Bulu Babi Secara Berkelanjutan Pada Kawasan Padang Lamun. Program Studi IImu Lingkungan Program Pascasarjana, Universitas Indonesia. Thesis (Tidak Dipublikasikan). 
Yusrika, Y. (2015). Beberapa Aspek Ekologi Dan Reproduksi Ikan Kulari (Lobocheilo Falcifer Cv: Cyprinidae) Di Sungai Batang Kuranji Padang Sumatera Barat (Doctoral Dissertation, Universitas Andalas). http://Scholar.Unand.Ac.Id/17824/2/Bab.\%20i.Pendahuluan\%281\%29.Pdf

Zakaria, I. J. (2013). Komunitas Bulu Babi (Echonoidea) Di Pulau Cingkuak, Pulau Sikuai Dan Pulau Setan Sumatera Barat. Prosiding Semirata 2013, 1(1). http://Jurnal.Fmipa.Unila.Ac.Id/Semirata/Article/View/681/501 